\title{
In the non-insect-transmissible line of onion yellows phytoplasma (OY-NIM), the plasmid-encoded transmembrane protein ORF3 lacks the major promoter region
}

Correspondence

Shigetou Namba

anamba@mail.ecc.u-tokyo.ac.jp
Received 9 January 2009

Revised 21 January 2009

Accepted 23 January 2009

\author{
Yoshiko Ishii, ${ }^{1}$ Shigeyuki Kakizawa, ${ }^{1}$ Ayaka Hoshi, ${ }^{1}$ Kensaku Maejima, ${ }^{1}$ \\ Satoshi Kagiwada, ${ }^{2}$ Yasuyuki Yamaji, ${ }^{1}$ Kenro Oshima ${ }^{3}$ \\ and Shigetou Namba ${ }^{1,3}$
}

${ }^{1}$ Laboratory of Plant Pathology, Department of Agricultural and Environmental Biology, Graduate School of Agricultural and Life Sciences, The University of Tokyo, 1-1-1 Yayoi, Bunkyo-ku, Tokyo 113-8657, Japan

${ }^{2}$ Department of Clinical Plant Science, Faculty of Bioscience and Applied Chemistry, Hosei University, 3-7-2 Kajinocho, Koganei, Tokyo 184-8584, Japan

${ }^{3}$ Laboratory of Clinical Plant Science, Department of Agricultural and Environmental Biology, Graduate School of Agricultural and Life Sciences, The University of Tokyo, 1-1-1 Yayoi, Bunkyo-ku, Tokyo 113-8657, Japan

\section{INTRODUCTION}

Phytoplasmas are phytopathogenic bacteria that cause more than 700 diseases in over 300 plant species (Lee et al., 2000). They lack cell walls and are pleomorphic in shape, with an average diameter of 200-800 nm (Doi et al., 1967; Hogenhout et al., 2008). Phytoplasmas belong to the Mollicutes, and are phylogenetically closely related to acholeplasmas (Hogenhout et al., 2008). Because culture of phytoplasmas in vitro has not been achieved, knowledge of their biology is limited (Christensen et al., 2005; Firrao et al., 2007; Hogenhout et al., 2008). Phytoplasmas inhabit phloem sieve elements in infected plants and are transmitted by sap-sucking insect vectors, in particular leafhoppers

Abbreviations: Amp, antigenic membrane protein; EcOY-DNA, extrachromosomal DNA of OY; OY, onion yellows phytoplasma; OY-M, mildly pathogenic line of OY; OY-NIM, non-insect-transmissible line of OY; OYW, severely pathogenic line of OY; pOY plasmid, plasmid of OY; RACE, rapid amplification of cDNA ends; Rep, replication initiator protein.

Three supplementary figures are available with the online version of this paper.
(Weintraub \& Beanland, 2006). After a leafhopper feeds on a phytoplasma-infected plant, the phytoplasmas multiply and spread throughout the insect's body. After a latency period of 7-80 days, the infected insect can transmit phytoplasmas to healthy plants (Hogenhout et al., 2008; Weintraub \& Beanland, 2006). Although some phytoplasmas may be transmitted at a low rate via plant seeds or insect eggs (Botti \& Bertaccini, 2006; Cordova et al., 2003; Khan et al., 2003), they are mainly spread via direct inoculation by the insects. Thus, it is crucial to identify factors involved in the host-microbe interaction for understanding their physiology and the mechanism of infection, and developing a strategy for controlling infection.

Onion yellows phytoplasma (OY) is a strain of 'Candidatus Phytoplasma asteris' (Oshima et al., 2004). Three lines of OY have been isolated: a severely pathogenic line (OY-W), a mildly pathogenic line (OY-M) and a non-insecttransmissible line (OY-NIM) (Oshima et al., 2001b; Shiomi et al., 1996). Because OY-NIM is derived from 
OY-M, comparing their genomes should provide clues to identify genes involved in insect transmissibility.

Plasmids often carry genes that are important for bacterial survival, such as antibiotic-resistance genes or genes involved in responses to environmental changes (Thomas, 2004). Many bacteria can adapt to specific environments by acquiring plasmids. In phytopathogenic bacteria, genes involved in pathogenicity, virulence and host specificity are often carried on plasmids (Vivian et al., 2001). Because many phytoplasmas contain plasmids, genes borne on these plasmids may serve important functions (Bai et al., 2006; Liefting et al., 2004, 2006; Nishigawa et al., 2003; Tran-Nguyen \& Gibb, 2006).

OY contains several extrachromosomal DNAs that can be classified into two types depending on their replication protein gene (rep). The extrachromosomal DNA (EcOYDNA) encodes a replication protein homologue to that of geminivirus, whereas the replication protein of plasmid pOY is homologous to that of other bacterial plasmids (Nishigawa et al., 2002a). OY-W contains two EcOYDNAs (EcOYW1 and EcOYW2) and a pOY plasmid (pOYW) (Kuboyama et al., 1998; Nishigawa et al., 2001, 2002a; Oshima et al., 2001a). OY-M contains both an EcOYDNA (EcOYM) and a pOY plasmid (pOYM), and OY-NIM also has both an EcOY-DNA (EcOYNIM) and a pOY plasmid (pOYNIM) (Nishigawa et al., 2002a, b, 2003). Interestingly, pOYNIM lacks orf 3 , which encodes a putative transmembrane protein and is carried on pOYW and pOYM (Nishigawa et al., 2002b). Therefore, we previously hypothesized that ORF3 could be involved in the insect transmissibility of OY (Nishigawa et al., 2002b). However, sequencing EcOYNIM revealed that it included the orf 3 gene (Nishigawa et al., 2003), which conflicts with our hypothesis. In this study, we found that ORF3 is not expressed in OYNIM-infected plants. To investigate the cause of this, we identified the transcriptional start sites and two putative promoter sequences of orf 3 , and showed that these promoter sequences were deleted or mutated on EcOYNIM. A possible link between the non-expression of ORF3 and the lack of functional orf3 promoters is suggested.

\section{METHODS}

Phytoplasma lines. 'Candidatus P. asteris' OY strain was isolated from plants in Saga Prefecture, Japan (Shiomi et al., 1996). Two derivative lines of OY (OY-W and OY-M) were maintained in garland chrysanthemums (Chrysanthemum coronarium) and leafhopper vectors (Macrosteles striifrons) (Oshima et al., 2001b). OY-W-infected plants showed typical symptoms (yellowing, dwarfing and stunting), whereas OY-M-infected plants still produced many lateral shoots and showed only mild leaf yellowing and almost no stunting. OY-NIM was isolated from OY-M by plant grafting without using insect vectors for about 2 years (Oshima et al., 2001b). OY-NIM showed the same symptoms as OY-M. OY-W-, OY-M- or OY-NIM-infected plants were maintained at $25{ }^{\circ} \mathrm{C}$ in a greenhouse with a $16 \mathrm{~h}$ light $/ 8 \mathrm{~h}$ dark photoperiod until used for analyses. OY-W- or OY-M-infected leafhoppers were prepared by feeding on OY-W- or OY-M-infected plants for 40 days. Healthy plants and leafhoppers were used as negative controls.
Preparation of antibody against ORF3 protein and Western blot analysis. The orf 3 of OY-W is $456 \mathrm{bp}$ in length and encodes a protein of 152 amino acids $(17.2 \mathrm{kDa})$ containing a transmembrane domain at both the $\mathrm{N}$ - and C-termini (Nishigawa et al., 2002b). The central, hydrophilic region of ORF3 between the two transmembrane domains (residues 38-119) was expressed by cloning in Escherichia coli. A 246 bp fragment of orf 3 was amplified from pOYW by PCR using primers ORF3a (5'-AGA ATT CCA TAT GAT TAA AGA TAA AAA TAA AGT TGA AAC CCA-3') and ORF3b (5'-TGA GCT CGA GTA CGA CTG CGA TAT CTT TAA TTA ATT-3'). The PCR product was digested with both $\mathrm{NdeI}$ and $\mathrm{XhoI}$, and cloned into pET-30a (Novagen). The histidine-tagged ORF3 construct was expressed in $E$. coli BL21-CodonPlus (DE3)-RIL cells (Stratagene). The cell extracts were applied to a nickel-NTA column (Novagen), washed with TBS buffer $(20 \mathrm{mM}$ Tris/HCl, pH 7.9 and $500 \mathrm{mM} \mathrm{NaCl})$, and the fusion protein was eluted with TBS buffer containing $1 \mathrm{M}$ imidazole. The molecular mass of the purified ORF3 protein was estimated by SDSPAGE as approximately $11 \mathrm{kDa}$ (see Supplementary Fig. S1, available with the online version of this paper), which is approximately equal to that of the central domain. An antibody against the partial ORF3 protein was generated as previously described (Kakizawa et al., 2001). The reactivity of the anti-ORF3 antibody was confirmed by Western blotting analysis against the purified ORF3 protein by a previously reported method (Kakizawa et al., 2004).

Immunohistochemical analysis. To confirm the expression level of ORF3, three antibodies were used in immunohistochemical analyses: anti-Amp (against an antigenic membrane protein of OY-W; Kakizawa et al., 2004), anti-Rep (against the replication protein encoded on pOYW; Oshima et al., 2001a) and anti-ORF3 (this study). Concentrations of the anti-Amp, anti-Rep and anti-ORF3 antibodies used in plant tissue sections were 1,100 and $100 \mu \mathrm{g} \mathrm{ml} \mathrm{m}^{-1}$, respectively, and those used in insect tissue sections were 1,100 and $1 \mu \mathrm{g} \mathrm{ml}^{-1}$, respectively.

To avoid sampling errors (such as effects of differences in individuals, protein expression only in restricted tissues, or sampling of healthy insects), five plants that showed typical symptoms of OY-W, OY-M or OY-NIM, and 15 insects sucking on OY-W- or OY-M-infected plants were collected.

Sections ( $\sim 2 \mathrm{~cm}$ in length) of stems were excised from OY-W-, OYM- or OY-NIM-infected garland chrysanthemum, respectively. We used the OY-NIM-infected plants sampled in 1999. The stem pieces were fixed, embedded in paraffin, and cut into $8 \mu \mathrm{m}$ sections with a PR-50 microtome (Yamato Scientific). OY-W- or OY-M-infected insects were sectioned by the same methods. The continuation of this method was performed according to Oshima et al. (2001b).

An Axio Imager $\mathrm{Z} 1$ microscope equipped with an AxioCam HRc camera controlled by AxioVision Rel. 4.6 software (equipment and software from Carl Zeiss MicroImaging) was used to collect images. Signal intensity was quantified using Adobe Photoshop version 7.0 (Adobe Systems) and ImageJ software (National Institutes of Health). Results are expressed as the mean \pm standard error. The significance of the difference between the mean values of the groups was evaluated by Student's $t$ test with Statcel software (OMS Publishing).

RNA isolation. Isogen reagent (Nippon Gene) was used to isolate total RNAs from OY-M-infected and healthy insects. To eliminate DNA contamination, the total RNAs were treated with DNase I (Takara) prior to using for cDNA synthesis, RT-PCR or $5^{\prime}$-RACE.

RT-PCR. Reverse transcription was performed using random primers and Reverse Transcriptase XL-AMV (Takara). Subsequent PCR amplification was performed using LA-Taq DNA polymerase and primers (Table 1). The amplified PCR products were visualized by agarose gel electrophoresis. 
Table 1. Oligonucleotide primers for RT-PCR and 5'-RACE

\begin{tabular}{|lll|}
\hline Primer & \multicolumn{1}{c}{ Sequence } & Annealing site \\
\hline EcOYM/ORF1(F) & AGAATTCCATATGCAGATATTCAATTATAACATAA & $5^{\prime}$ end of orf1 \\
EcOYM/ORF1(R) & CGAGCTCGAGGGGGTTTTTTTATAATCTTTTTTA & $3^{\prime}$ end of orf1 \\
EcOYM/ORF1-nested(R) & TGAGCTCGAGTGGTTGGGTTAATTCTGATTTAGGA & Within orf1 \\
EcOYM/ORF2(F) & AGAATTCCATATGAAAACCAATAATCAAAAAAAAT & $5^{\prime}$ end of orf2 \\
EcOYM/ORF2(R) & CGAGCTCGAGATAAATTAATTCTTGTTTAACAGTT & $3^{\prime}$ end of orf2 \\
EcOYM/ORF2-nested(R) & TGAGCTCGAGACCCTCGGGGTTGAACTCCCTAATAG & Within orf2 \\
EcOYM/ORF3(F) & AGAATTCCATATGAATAAAAAAAGAAAAATTATATTAA & $5^{\prime}$ end of orf3 \\
EcOYM/ORF3(R) & TGAGCTCGAGAGCTAATAAAGCAAGAGGAGCTGCT & $3^{\prime}$ end of orf3 \\
EcOYM/ORF3-nested(R) & TGAGCTCGAGAGCTGCACCTGTGGCAAGAGTTACT & Within orf3 \\
EcOYM/ORF3-nested2(R) & TGAGCTCGAGTGCAATAAAGATAGTCCACATTATT & Within orf3 \\
EcOYM/ORF4(F) & AGAATTCCATATGTTAAATAAAGTACAACTAATCG & $5^{\prime}$ end of orf4 \\
EcOYM/ORF4(R) & TGAGCTCGAGAGCTAATAAAGCAAGAGGAGCTGCT & $3^{\prime}$ end of orf4 \\
\hline
\end{tabular}

5'-RACE and promoter prediction. To identify the $5^{\prime}$ end of mRNA derived from orf3, 5'-RACE analysis was performed using the Gene Racer kit (Invitrogen). First, $7 \mu \mathrm{g}$ total RNA from OY-M-infected insects was treated with tobacco acid pyrophosphatase to eliminate two of the three RNA 5'-phosphates. Gene Racer 5'-RNA oligonucleotides (5'-CGA CUG GAG CAC GAG GAC ACU GAC AUG GAC UGA AGG AGU AGA AA-3') were ligated to the total RNA using T4 RNA ligase, and the total RNA was reverse-transcribed using Cloned Avian Myeloblastosis Virus Reverse Transcriptase and random primers. GeneRacer 5' -primers (5'-CGA CTG GAG CAC GAG GAC ACT GA-3') and gene-specific primers (Table 1) were used for initial PCRs. GeneRacer $5^{\prime}$-nested primer (5'-GGA CAC TGA CAT GGA CTG AAG GAG TA-3') and gene-specific nested primers (Table 1) were used for nested PCRs. The nested PCR products were visualized by agarose gel electrophoresis. They were cloned using the pGEM-T Easy vector system I (Promega). Nucleotide sequences were determined by the dideoxynucleotide chain-termination method using an ABI Prism 3130 DNA sequencer (Applied Biosystems). We identified the $5^{\prime}$ end of each nested PCR product as a putative transcriptional start site of orf 3 . The -10 and -35 regions of the orf 3 and amp gene promoters were predicted by the Mulligan method (Mulligan et al., 1984) using GENETYX-MAC software (GENETYX).

\section{RESULTS}

\section{Immunohistochemical analysis of ORF3}

To compare expression levels and distributions of Amp, Rep and ORF3 proteins in phytoplasma-infected plants, immunohistochemical analyses were performed using individual antibodies.

In the OY-W-infected and the OY-M-infected plants, blue signals were observed in the phloem tissues of the main stems by anti-Amp, anti-Rep and anti-ORF3 antibodies (at concentrations of 1,100 and $100 \mu \mathrm{g} \mathrm{ml}^{-1}$, respectively) (Fig. 1a, b, d, e, g and h). The signal intensities of ORF3 were approximately equal to those of Rep at the same antibody concentrations (Fig. 1j). In the OY-NIM-infected plants, specific signals were also observed by anti-Amp and anti-Rep antibodies (Fig. 1c and f), but not by anti-ORF3 antibody (Fig. 1i). The signal intensities of ORF3 were significantly lower than those of Rep $(P<0.0005$; Fig. $1 \mathrm{j})$ and approximately equal to background level (data not shown), suggesting that OY-NIM does not express ORF3 protein. Similar results were also obtained from the OY-Winfected plants (20/20 sections; $100 \%)$, the OY-M-infected plants (19/20 sections; $95 \%)$, and the OY-NIM-infected plants (20/20 sections; $100 \%)$.

Immunohistochemical analyses were also performed using phytoplasma-infected insects. In the OY-W-infected and the OY-M-infected insects, blue signals were observed in the guts, salivary glands and fat bodies by anti-Amp, antiRep and anti-ORF3 antibodies (at concentrations of 1, 100 and $1 \mu \mathrm{g} \mathrm{ml}^{-1}$, respectively) (Fig. $2 \mathrm{~b}, \mathrm{c}, \mathrm{e}, \mathrm{f}, \mathrm{h}$ and i). The signal intensities of ORF3 were higher than those of Rep despite the lower antibody concentration $(P<0.005$; Fig. $2 \mathrm{j}$ ). Similar results were also obtained from the OY-Winfected insects $(20 / 20$ sections; $100 \%)$ and the OY-Minfected insects (19/20 sections; $95 \%)$.

\section{Analysis of the transcriptional units of orf3}

To detect transcription products of EcOYM-encoded genes (orf1-5), RT-PCR analysis was performed using total RNA isolated from OY-M-infected insects as the template. All orf fragments were amplified (Supplementary Fig. S2), indicating that all of these genes were transcribed in phytoplasma cells. We also checked that no fragment was amplified without reverse transcription, to prove the absence of DNA contamination in the RNA preparations (Supplementary Fig. S2). To identify a transcriptional unit of orf3, we performed RT-PCR analyses of intergenic regions of orf1-2, orf2-3 and orf3-4 (Fig. 3a). All orf fragments were amplified (Fig. 3b), suggesting that each orf was co-transcribed with its neighbouring genes. However, the orf1-2 fragment was amplified at lower levels than the others. These results were repeatedly observed in all of three experiments, suggesting that orf1 would be transcribed alone while orf 3 would be co-transcribed with orf 2 and orf4. 


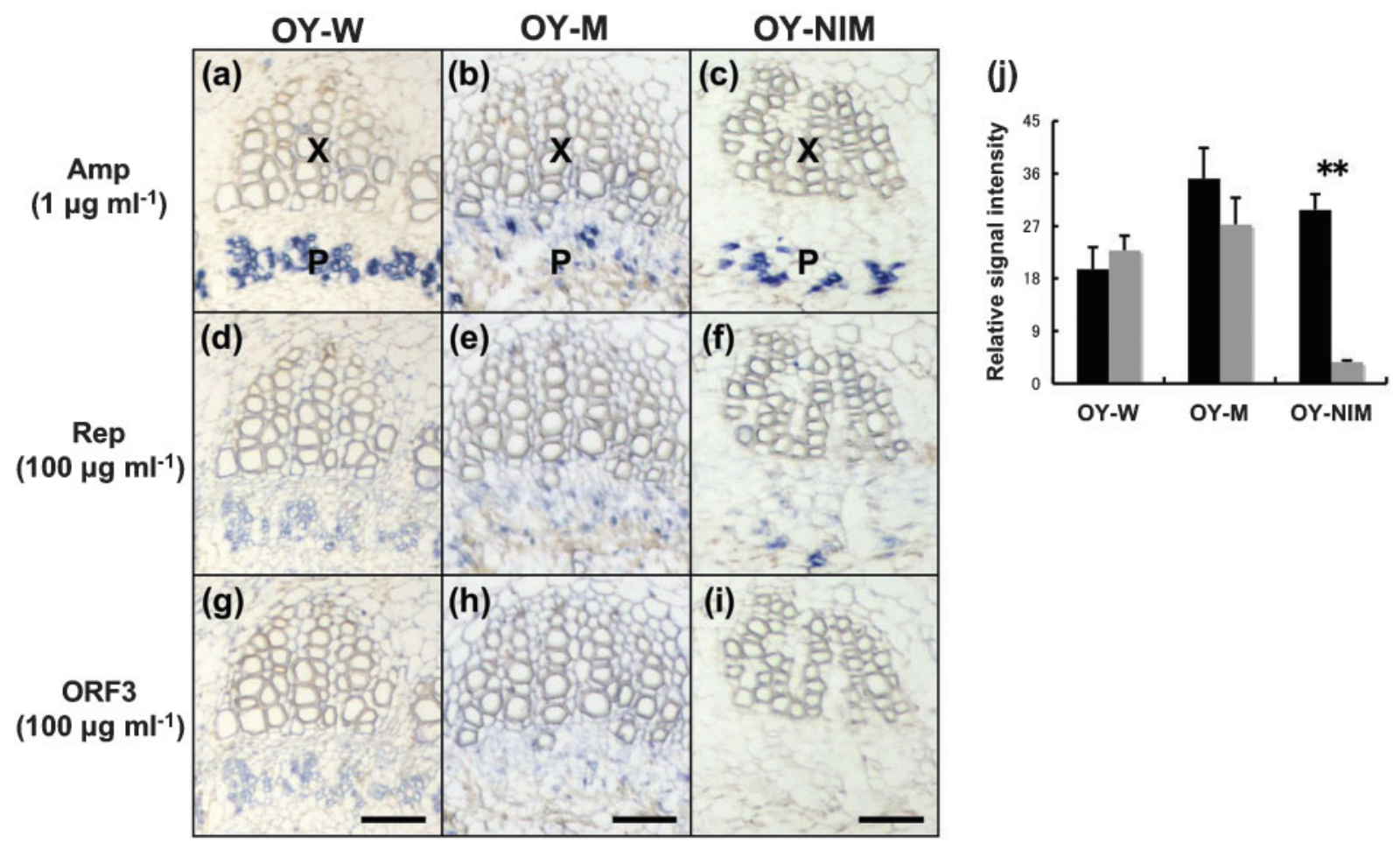

Fig. 1. (a-i) Immunohistochemical analyses of phytoplasma-infected garland chrysanthemum tissue sections. (a, d, g) OY-W infected plants, (b, e, h) OY-M infected plants, (c, f, i) OY-NIM infected plants. (a-c) Anti-Amp antibody, (d-f) anti-Rep antibody, ( $g-i)$ anti-ORF3 antibody. Each phytoplasma-infected plant was serially sectioned at $8 \mu m$ thickness. $X$ and $P$ indicate xylem and phloem. Blue signals represent the presence of phytoplasma. Scale bars, $0.1 \mathrm{~mm}$. (j) Comparison of relative signal intensities detected by immunohistochemical analyses of phytoplasma-infected plants. The relative signal intensities are means of 20 sections, with standard error of the mean. Black and grey bars indicate relative signal intensities of Rep and ORF3, respectively. Their values are normalized to that of Amp. ${ }^{* *}$ indicates a value that is statistically significant $(P<0.0005$, Student's $t$ test).

\section{Identification of the putative transcriptional start sites of orf3 by $5^{\prime}$-RACE}

To identify the $5^{\prime}$ end of mRNA derived from orf $3,5^{\prime}$ RACE analysis was performed using total RNA isolated from OY-M-infected insects. Random primers were used for reverse transcription, and adaptor primers and genespecific primers were used for initial and nested PCRs (Table 1). The nested PCR products were cloned and sequenced.

PCRs were performed using an initial primer and a nested primer that anneal to the $3^{\prime}$ end and within orf 3 , respectively (Fig. 4b, row 4). Two fragments were amplified (Fig. 4a, lane 4), suggesting that orf3 is transcribed from two putative transcriptional start sites.

To investigate whether orf 3 transcription starts at the upstream region of orf1, PCRs were performed with an initial primer at the $3^{\prime}$ end of orf 3 and a nested primer at the $3^{\prime}$ end of orf 1 . Two fragments, of $\sim 300 \mathrm{bp}$ and $\sim 1.8 \mathrm{kbp}$, were amplified (Fig. $4 \mathrm{a}$ and b, lane 1). Sequencing these fragments revealed that the $300 \mathrm{bp}$ fragment was orf1 while the $1.8 \mathrm{kbp}$ fragment was a non-specific product, identified as insect rDNA. PCR amplification with an initial primer at the $3^{\prime}$ end of orf 2 and a nested primer at the $3^{\prime}$ end of orf 1 yielded a $\sim 500 \mathrm{bp}$ fragment identified as orf1 (Fig. 4a and b, lane 5). Similarly, amplification with an initial and a nested primer located respectively at the $3^{\prime}$ end of orf 1 and within orf1 yielded two products, of $\sim 400 \mathrm{bp}$ and $\sim 600 \mathrm{bp}$, respectively (Fig. $4 \mathrm{a}$ and b, lane 7 ). The $400 \mathrm{bp}$ sequence was identical to that of orf 1 whereas the $600 \mathrm{bp}$ fragment was similar to insect rDNA. As a whole these results showed that all mRNA transcripts carrying orf1 sequences start within orf1 and suggest that one of the putative transcriptional starts of orf 3 is located within orf1.

To investigate whether orf 3 transcription starts at the upstream region of orf2, PCRs were performed using an initial primer at the $3^{\prime}$ end of orf 3 and two nested primers at the $3^{\prime}$ end of orf 2 and the $5^{\prime}$ end of orf 3 , respectively (Fig. 4b, rows 2 and 3). Both PCR amplifications yielded a $\sim 650$ bp product (Fig. 4a, lanes 2 and 3). Sequences of these 650 bp fragments were identical to that of orf2, and their $5^{\prime}$ ends started at the orfl-2 intergenic region. This 


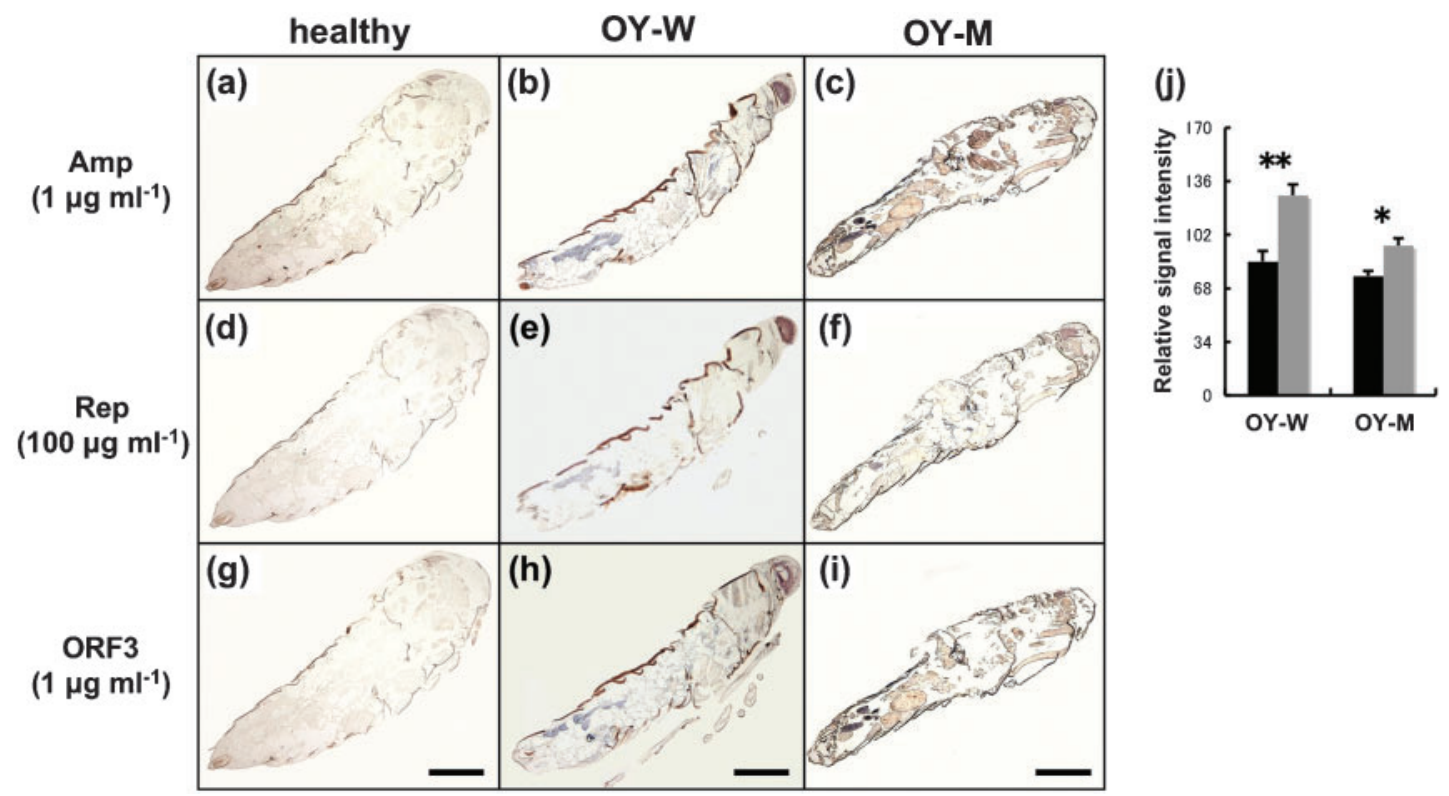

Fig. 2. (a-i) Immunohistochemical analyses of leafhopper (Macrosteles striifrons) tissue sections. (a, $d, g)$ Healthy insects, (b, e, h) OY-W infected insects, (c, f, i) OY-M infected insects. (a-c) Anti-Amp antibody, (d-f) anti-Rep antibody, (g-i) anti-ORF3 antibody. Each phytoplasma-infected insect was serially sectioned at $8 \mu \mathrm{m}$ thickness. Blue signals represent the presence of phytoplasma. Scale bars, $0.5 \mathrm{~mm}$. (j) Comparison of relative signal intensities detected by immunohistochemical analyses of phytoplasma-infected insects. Details as for Fig. 1(i). * and ${ }^{* *}$ indicate values that are statistically significant $(P<0.005$ and $P<0.0005$, respectively, Student's $t$ test).

result suggests that a putative transcriptional start site of orf 3 is located in the orf1-2 intergenic region in addition to the one within orf1.

Finally, PCRs were performed using an initial primer and a nested primer that anneal to the $3^{\prime}$ end of orf 2 and within orf2, respectively (Fig. 4b, row 6). As a result, $\sim 600 \mathrm{bp}$ and $\sim 1 \mathrm{kbp}$ fragments were amplified (Fig. 4a, lane 6). The sequence of the $600 \mathrm{bp}$ fragment was identical to that of orf 2 , and its $5^{\prime}$ ends started at the orf1-2 intergenic region. The sequence of the $\sim 1 \mathrm{kbp}$ fragment was identical to that of orf1-2, with its $5^{\prime}$ end starting within orf1. Taken together, these results indicate that orf3 transcription starts from two distinct promoters located at the $5^{\prime}$ end of orf1 and within the orf1-2 intergenic region, respectively.

We sequenced 37 clones encoding inserts whose $5^{\prime}$ ends started at the inside of orf1 (Fig. 4a, lane 1) and 59 clones encoding inserts whose $5^{\prime}$ ends started at the orf $1-2$ intergenic region (29 and 30 clones in Fig. 4a, lanes 2 and 3, respectively). The positions of the $5^{\prime}$ ends of nested PCR products (putative transcriptional start sites) are shown in Fig. 5(a). Although multiple $5^{\prime}$ ends of the orf $3 \mathrm{mRNA}$ were detected, residues A located $46 \mathrm{bp}$ downstream of the orf $15^{\prime}$ end, and C located 49 bp downstream of the $5^{\prime}$ end of the orf1-2 intergenic region were considered as the main transcriptional starts by a majority decision (Fig. 5a, asterisk).

\section{Promoter prediction and comparative analysis}

We predicted orf 3 promoters using a promoter-prediction program, and compared their sequences between EcOYM and EcOYNIM. The putative promoters were identified in the upstream region of the two putative transcriptional start sites of orf3 (Fig. 5a and b). We designated the promoter located within orf1 as ORF3-pro1, and that located in the orf1-2 intergenic region as ORF3-pro2. In the ORF3-prol sequences, there were two nucleotide differences between EcOYM and EcOYNIM (accession nos AB076263 and AB097150; Fig. 5b). Surprisingly, the $157 \mathrm{bp}$ sequence containing ORF3-pro2, present in EcOYM, was deleted in EcOYNIM (accession nos AB076263 and AB097150; Fig. 5b).

Sequence comparisons of the -10 and -35 regions of ORF3-pro2 with those of the 16S rDNA (Jung et al., 2003) and amp gene promoters of OY-M predicted with the same program revealed five nucleotide differences (Fig. 5b).

\section{DISCUSSION}

Characterization of the $5^{\prime}$ ends of orf 3 mRNA transcripts indicates that orf3 is transcribed from two distinct promoters, ORF3-pro1 and ORF3-pro2, located at the 5' end of orf 1 and in the orf1-2 intergenic region, respectively. ORF3-pro2 appears to be the major orf3 promoter for three reasons: the orf1-2 intergenic region was poorly amplified 
(a)

1258 bp

$1070 \mathrm{bp}$

$803 \mathrm{bp}$

(b)

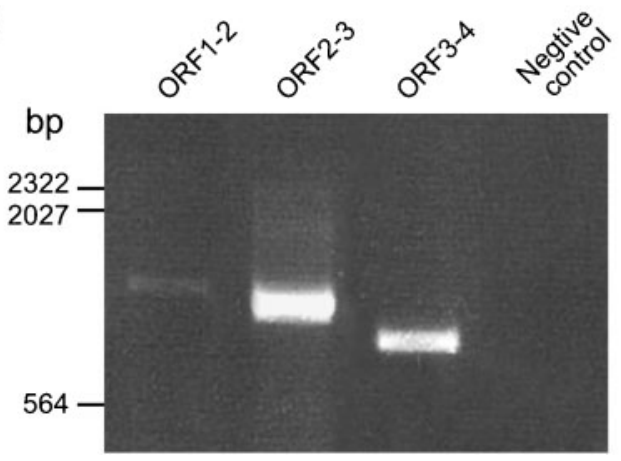

Fig. 3. Analysis of the transcriptional units of orf3. (a) Schematic representation of the intergenic regions on EcOYM amplified by RT-PCR. Lines and numbers represent the regions amplified by RT-PCR and the expected lengths, respectively. (b) Transcriptional analysis of the intergenic regions on EcOYM. RT-PCR of the intergenic regions on EcOYM was performed using total RNA isolated from OY-M-infected insects. To prove the absence of DNA contamination in the total RNA, PCR analysis of the OY-M amp gene was performed without reverse transcription (negative control).

by RT-PCR (Fig. 3b, orf1-2), the orf1-3 transcription product was not always detected by $5^{\prime}$-RACE whereas the orf2-3 was consistently detected using all primer sets tested (Fig. 4a, lanes 2 and 3), and the transcription products from the orf1-2 intergenic region were detected more than that from within orf 1 by competitive 5 -RACE for forward primer (Fig. 4a, lanes 4 and 6).

For each of the two promoter regions, multiple transcriptional starts were detected (Fig. 5a). This could result from slipping of RNA polymerase or, alternatively, from limited degradation of the mRNA 5' ends. Such heterogeneity of transcription initiation sites has also been reported in Mycoplasma pneumoniae (Sorensen et al., 1993; Wagner et al., 1990; Weiner et al., 2000; Wilson et al., 1987, 1992; Xiong \& Reznikoff, 1993).

Homologues of orf1-3 on EcOYM are carried on pOYM (Supplementary Fig. S3; Nishigawa et al., 2003). Because the nucleotide sequence identities of orf1 and orf2 on EcOYM and pOYM are $89.3 \%$ and $73.8 \%$, respectively, we were able to determine the targeted plasmid, i.e. EcOYM or pOYM, of the 5'-RACE products. However, the nucleotide sequences of orf3 encoded on EcOYM and pOYM are (a)

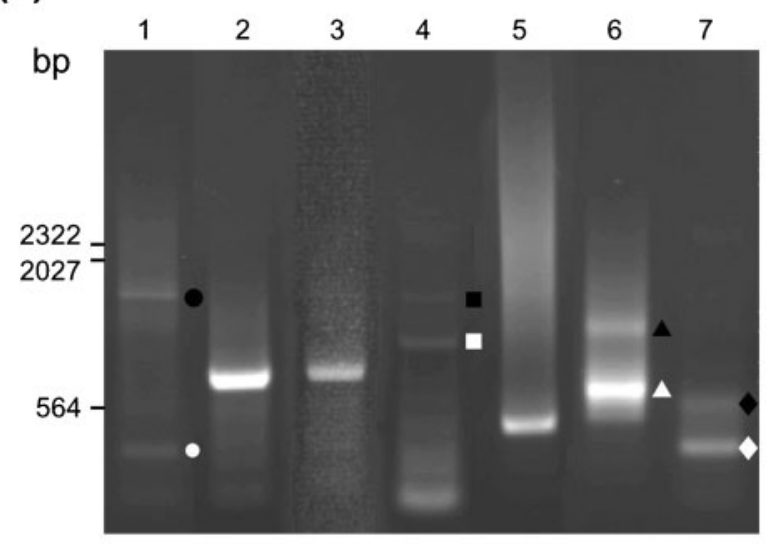

(b)

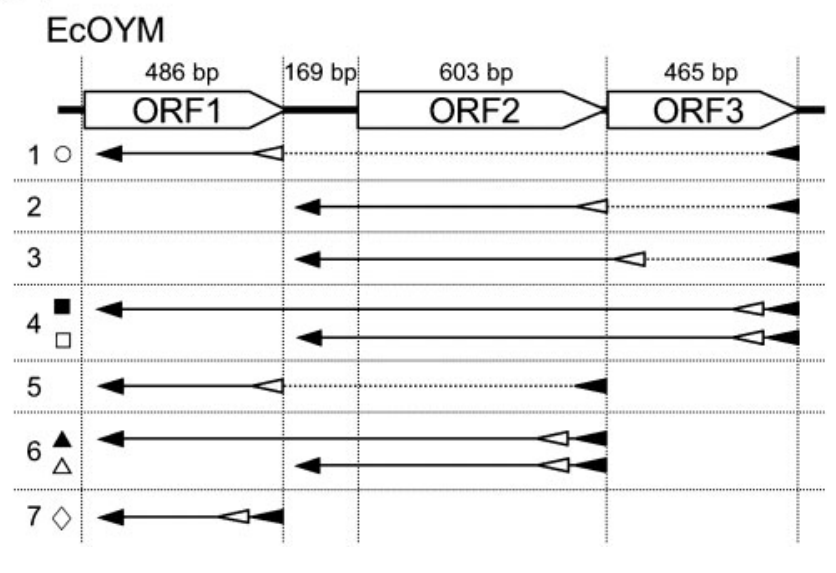

Fig. 4. Analysis of the $5^{\prime}$ ends of orf 3 mRNA transcripts. (a) $5^{\prime}-$ RACE analysis using total RNA isolated from OY-M-infected insects. Lane numbers and symbols (open and filled circles, squares, triangles and diamonds) to the right of fragments correspond to those in (b). (b) Schematic representation of the EcOYM regions amplified by 5 '-RACE. Each number on the left corresponds to a lane in (a). Black and white arrowheads indicate initial and nested primers, respectively. Symbols correspond to those in (a). The solid line and solid line plus dotted line correspond to the regions amplified by nested and initial PCRs, respectively. The fragments to the left of the filled circle in lane 1 and the filled diamond in lane 7 of (a) were non-specific bands (rDNA of insects); these two symbols are not shown in (b).

identical and could not be distinguished. When 5'-RACE was performed with initial and nested primers annealing respectively to the $3^{\prime}$ and $5^{\prime}$ ends of orf3, a single fragment was detected (Fig. 4a, lane 3). Although this fragment was expected to contain two distinct products, derived from EcOYM and pOYM, all of the 30 clones sequenced contained the orf2 of EcOYM. This result suggested that orf3 was mainly expressed from EcOYM rather than pOYM. It remains unclear why the homologue of orf3 is carried on pOYM despite its low expression level. 
(a)

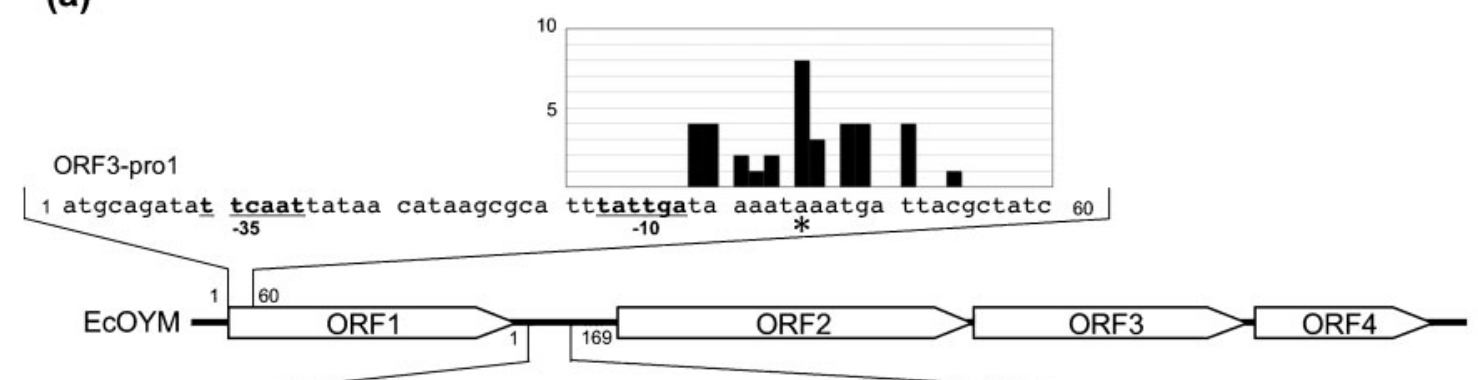

ORF3-pro2

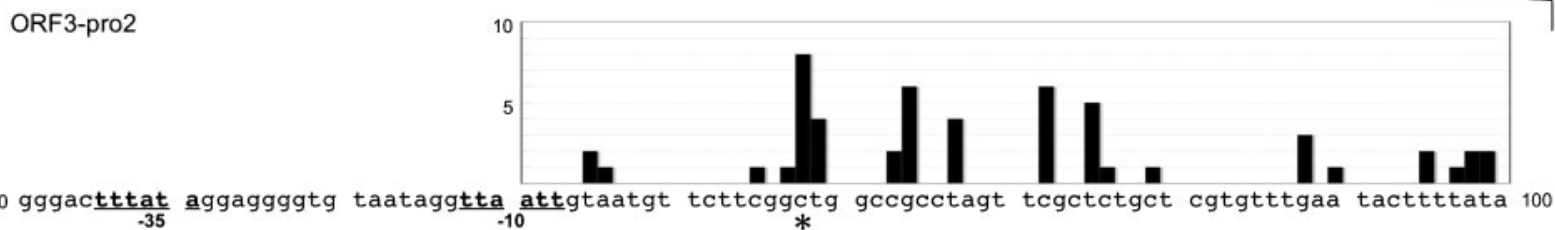

(b)

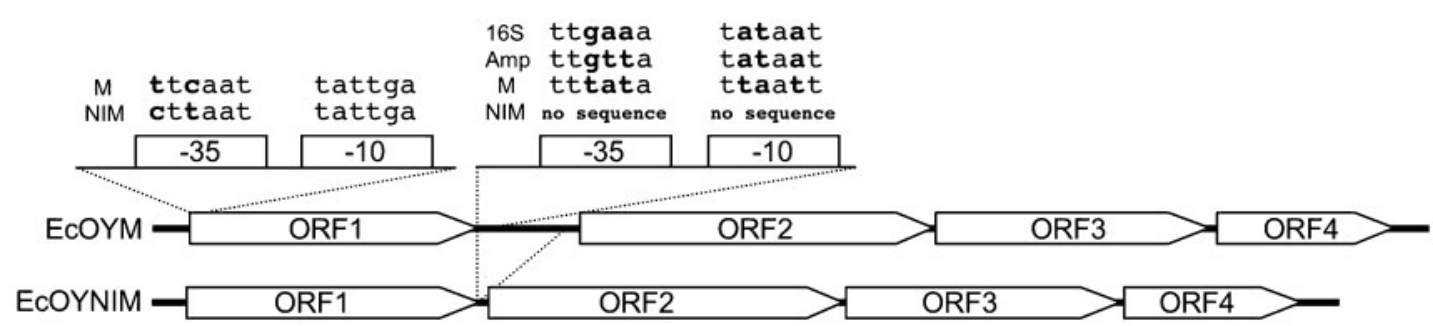

Fig. 5. Identification of the putative transcriptional start sites and promoters of orf3. (a) Schematic representation of the putative transcriptional start sites of orf3. Nucleotide sequences indicate the regions surrounding the $5^{\prime}$ ends of mRNA derived from orf3. The two graphs represent numbers of $5^{\prime}$ ends of the clones resulting from cloning and sequencing of $5^{\prime}-\mathrm{RACE}$ products, and the $5^{\prime}$ ends correspond to the nucleotide sequences indicated under the graphs. Asterisks indicate the nucleotide positions corresponding to the $5^{\prime}$ ends of the most abundant clones. Underlined sequences indicate the putative -35 and -10 regions of ORF3-pro1 and ORF3-pro2. (b) Comparison of the OY gene promoters. The promoter sequences of orf3 are compared with those of the 16S rRNA and amp genes. Nucleotide differences are indicated in bold.

\section{Relationship between ORF3 and insect transmissibility}

We found that promoter sequences of orf3 were mutated or deleted on EcOYNIM (Fig. 5b). It has been previously demonstrated that both orf3 and orf4 are absent from pOYNIM (Nishigawa et al., 2002b). These results suggest that the expression level of ORF3 may be significantly lower in OY-NIM than in OY-M. This hypothesis is consistent with the fact that ORF3 was not detected in the OY-NIM-infected plants (Fig. 1i and $\mathrm{j}$ ).

The function of ORF3 remains unclear but it is probably required for phytoplasmal survival in insects rather than plants, because OY-NIM can survive in plant hosts despite the lack of the ORF3 product. ORF3 is thought to be a transmembrane protein because two hydrophobic regions at the $\mathrm{N}$ - and C-terminus, and a Sec-translocation signal sequence were predicted (Nishigawa et al., 2002b).
Therefore, ORF3 would localize to the cell surface of the phytoplasma, with its hydrophilic domain accessible to interactions with host components. In general, phytoplasmal transmembrane proteins such as ORF3 are thought to play a crucial role in the interaction with hosts, because phytoplasmas lack cell walls and reside intracellularly. It will be interesting to elucidate the interactions between ORF3 and insect proteins.

Several surface proteins involved in insect transmissibility have been reported in the phytopathogenic bacterium Spiroplasma citri. Among them, P58 and SARP1 are thought to play a role in adherence and invasion of insect cells (Berg et al., 2001; Ye et al., 1997; Yu et al., 2000). Also, spiralin is required for efficient transmission by the vector insect (Duret et al., 2003; Killiny et al., 2005). P32 encoded on a $S$. citri plasmid has been associated with insect transmissibility (Berho et al., 2006a, b; Killiny et al., 2006). It has also been reported that the plasmids of Borrelia 
burgdorferi have important functions for survival of the bacteria in the arthropod vector (Hovius et al., 2007). B. burgdorferi, the causative agent of Lyme disease, parasitizes animals and is predominantly transmitted by arthropod vectors. The surface protein OspA encoded on the $B$. burgdorferi linear plasmid is essential for the colonization and survival in tick midguts (Neelakanta et al., 2007; Stewart et al., 2005; Yang et al., 2004). The surface protein OspC encoded on the B. burgdorferi circular plasmid is involved in the invasion of and attachment to tick salivary glands (Grimm et al., 2004; Pal et al., 2004; Stewart et al., 2005). These reports suggest that bacterial plasmids often play an important role in survival in arthropod vectors. The results of this study suggest that the plasmid-encoded orf 3 gene may be involved in the survival of OY in insect hosts. Although it remains unclear why determinants of insect transmissibility are carried on plasmids, our results suggest that, as in other bacteria, OY plasmids could be involved in insect transmissibility of the phytoplasma. However, an ORF3 homologue is not found in the whole genomic sequence of 'Candidatus Phytoplasma mali' (data not shown: Kube et al., 2008). Additionally, several strains of 'Candidatus P. asteris' do not contain plasmids. Further analyses are needed to elucidate the relationships between phytoplasmal plasmids and insect transmissibility.

It was recently reported that Amp of OY-W interacted with microfilaments of the vector insect and that the formation of Amp-microfilament complexes was required for insect transmissibility (Suzuki et al., 2006). For successful transmission, phytoplasmas must pass through the intestine, enter the haemocoel and infect several tissues including the salivary glands (Hogenhout et al., 2008; Webb et al., 1999). Besides Amp, many other factors are considered to be required in each of the steps (Purcell, 1982), and ORF3 could be one of them. The complete nucleotide sequences of several phytoplasma plasmids have been reported, including those of beet leafhopper-transmitted virescence agent (BLTVA), tomato big bud (TBB), 'Candidatus Phytoplasma australiense', and aster yellows phytoplasma strain of witches' broom (AY-WB) (Bai et al., 2006; Liefting et al., 2004, 2006; Tran-Nguyen \& Gibb, 2006). Among them, only the plasmids of 'Candidatus P. australiense' and AY-WB encode orf3 homologues. Therefore, it is likely that factors involved in the adaptation to insect hosts differ among phytoplasma strains. This may be related to the large diversity of insect vectors among phytoplasma strains (Weintraub \& Beanland, 2006).

\section{Environmental response system of phytoplasma}

Immunological studies revealed that Amp protein was highly expressed regardless of the host (Kakizawa et al., 2004). Similarly, the Rep protein was equally expressed in plant and insect tissues, although to a lower level. In contrast, whereas in OY-W- and OY-M-infected plants ORF3 and Rep were equally expressed (Fig. 1j), the expression level of ORF3 in OY-W- and OY-M-infected insects was higher than that of Rep, in spite of the lower antibody concentration used (Fig. 2j). Even though quantification of the proteins cannot be achieved from these immunohistochemical analyses, the results clearly indicate that ORF3 is preferentially expressed in insects rather than in plants, suggesting the ability for the phytoplasmas to adapt to different intracellular environments. This also suggests that phytoplasmas might possess an environmental response system.

\section{Promoters and transcriptional factors of phytoplasmas}

We predicted putative promoters of both the orf 3 and amp genes, and compared them with the putative promoter of the 16S rRNA gene of OY-M (Jung et al., 2003). The promoter sequence of the amp gene was similar to that of the $16 \mathrm{~S}$ rRNA gene, and their -10 sequences were identical (Fig. 5b). However, the promoter sequence of orf3 differed from those of the 16S rRNA and amp genes, which were thought to be expressed constitutively. Our immunohistochemical analyses suggest a different expression of ORF3 between plant and insect hosts, which may be related to the differences in promoter sequence (Figs 1 and 2). Taking into account the high expression levels of ORF3 in insect cells (Fig. $2 \mathrm{~h}$ and $\mathrm{i}$ ), the orf3 promoter might function specifically when phytoplasma infects an insect vector.

The $\sigma$ (sigma) factor of RNA polymerase targets transcription initiation to specific promoter sequences (Wade et al., 2006). Most bacteria have multiple $\sigma$ factors that are required for complex cellular processes such as stress responses, morphogenesis and virulence (Gruber \& Gross, 2003). Although mycoplasma and phytoplasma genomes encode few $\sigma$ factors (Fraser et al., 1995), at least two $\sigma$ factors, $r p o D$ and $f l i A$, were identified in the OY-M genome (Oshima et al., 2004). These $\sigma$ factors might be involved in changing gene expression. Further analyses are necessary to elucidate the relationships between promoter sequences and $\sigma$ factors in phytoplasmas.

\section{Conclusions}

We have shown that the non-insect-transmissible line OYNIM does not express ORF3, probably due to the loss of DNA sequences including the major transcription promoter. These findings suggest that ORF3 might be a key element for the OY phytoplasma to adapt to its insect host. However, further analyses will be required to determine whether ORF3 is essential for insect transmission.

\section{ACKNOWLEDGEMENTS}

We thank Dr Wei Wei for the immunohistochemical analysis that was performed at Laboratory of Plant Pathology, Tokyo, Japan. This work was supported by the Japan Society for the Promotion of Science (JSPS) and a Grant-in-Aid for Scientific Research from the Japan Society for the Promotion of Science (category S of Scientific Research Grant 16108001). 


\section{REFERENCES}

Bai, X., Zhang, J., Ewing, A., Miller, S. A., Jancso Radek, A., Shevchenko, D. V., Tsukerman, K., Walunas, T., Lapidus, A. \& other authors (2006). Living with genome instability: the adaptation of phytoplasmas to diverse environments of their insect and plant hosts. J Bacteriol 188, 3682-3696.

Berg, M., Melcher, U. \& Fletcher, J. (2001). Characterization of Spiroplasma citri adhesion related protein SARP1, which contains a domain of a novel family designated sarpin. Gene 275, 57-64.

Berho, N., Duret, S. \& Renaudin, J. (2006a). Absence of plasmids encoding adhesion-related proteins in non-insect-transmissible strains of Spiroplasma citri. Microbiology 152, 873-886.

Berho, N., Duret, S., Danet, J. L. \& Renaudin, J. (2006b). Plasmid pSci6 from Spiroplasma citri GII-3 confers insect transmissibility to the non-transmissible strain S. citri 44. Microbiology 152, 2703-2716.

Botti, S. \& Bertaccini, A. (2006). Phytoplasma infection through seed transmission: further observations. In Abstracts, 16th International Organization of Mycoplasmology Conference, Cambridge, UK, p. 76.

Christensen, N. M., Axelsen, K. B., Nicolaisen, M. \& Schulz, A. (2005). Phytoplasmas and their interactions with hosts. Trends Plant Sci 10, 526-535.

Cordova, I., Jones, P., Harrison, N. A. \& Oropeza, C. (2003). In situ PCR detection of phytoplasma DNA in embryos from coconut palms with lethal yellowing disease. Mol Plant Pathol 4, 99-108.

Doi, Y., Teranaka, M., Yora, K. \& Asuyama, H. (1967). Mycoplasma or PLT group-like microorganisms found in the phloem elements of plants infected with mulberry dwarf, potato witches' broom, aster yellows or paulownia witches' broom. Ann Phytopathol Soc Jpn 33, 259-266.

Duret, S., Berho, N., Danet, J. L., Garnier, M. \& Renaudin, J. (2003). Spiralin is not essential for helicity, motility, or pathogenicity but is required for efficient transmission of Spiroplasma citri by its leafhopper vector Circulifer haematoceps. Appl Environ Microbiol 69, 6225-6234.

Firrao, G., Garcia-Chapa, M. \& Marzachì, C. (2007). Phytoplasmas: genetics, diagnosis and relationships with the plant and insect host. Front Biosci 12, 1353-1375.

Fraser, C. M., Gocayne, J. D., White, O., Adams, M. D., Clayton, R. A., Fleischmann, R. D., Bult, C. J., Kerlavage, A. R., Sutton, G. \& other authors (1995). The minimal gene complement of Mycoplasma genitalium. Science 270, 397-403.

Grimm, D., Tilly, K., Byram, R., Stewart, P. E., Krum, J. G., Bueschel, D. M., Schwan, T. G., Policastro, P. F., Elias, A. F. \& Rosa, P. A. (2004). Outer-surface protein $\mathrm{C}$ of the Lyme disease spirochete: a protein induced in ticks for infection of mammals. Proc Natl Acad Sci U S A 101, 3142-3147.

Gruber, T. M. \& Gross, C. A. (2003). Multiple sigma subunits and the partitioning of bacterial transcription space. Annu Rev Microbiol 57, 441-466.

Hogenhout, S. A., Oshima, K., Ammar, el-D., Kakizawa, S., Kingdom, H. N. \& Namba, S. (2008). Phytoplasmas: bacteria that manipulate plants and insects. Mol Plant Pathol 9, 403-423.

Hovius, J. W., van Dam, A. P. \& Fikrig, E. (2007). Tick-host-pathogen interactions in Lyme borreliosis. Trends Parasitol 23, 434-438.

Jung, H. Y., Miyata, S., Oshima, K., Kakizawa, S., Nishigawa, H., Wei, W., Suzuki, S., Ugaki, M., Hibi, T. \& Namba, S. (2003). First complete nucleotide sequence and heterologous gene organization of the two rRNA operons in the phytoplasma genome. DNA Cell Biol 22, 209-215.

Kakizawa, S., Oshima, K., Kuboyama, T., Nishigawa, H., Jung, H. Y., Sawayanagi, T., Tsuchizaki, T., Miyata, S., Ugaki, M. \& Namba, S.
(2001). Cloning and expression analysis of phytoplasma protein translocation genes. Mol Plant Microbe Interact 14, 1043-1050.

Kakizawa, S., Oshima, K., Nishigawa, H., Jung, H. Y., Wei, W., Suzuki, S., Tanaka, M., Miyata, S., Ugaki, M. \& Namba, S. (2004). Secretion of immunodominant membrane protein from onion yellows phytoplasma through the Sec protein-translocation system in Escherichia coli. Microbiology 150, 135-142.

Khan, A. J., Botti, S., Al-Subhi, A. M., Zaidi, M. A., Altosaar, I., Alma, A. \& Bertaccini, A. (2003). Molecular characterization of the $16 S \mathrm{rRNA}$ gene of phytoplasmas detected in two leafhopper species associated with alfalfa plants infected with witches' broom in Oman. Phytopathol Mediterr 42, 257-267.

Killiny, N., Castroviejo, M. \& Saillard, C. (2005). Spiroplasma citri spiralin acts in vitro as a lectin binding to glycoproteins from its insect vector Circulifer haematoceps. Phytopathology 95, 541-548.

Killiny, N., Batailler, B., Foissac, X. \& Saillard, C. (2006). Identification of a Spiroplasma citri hydrophilic protein associated with insect transmissibility. Microbiology 152, 1221-1230.

Kube, M., Schneider, B., Kuhl, H., Dandekar, T., Heitmann, K., Migdoll, A. M., Reinhardt, R. \& Seemüller, E. (2008). The linear chromosome of the plant-pathogenic mycoplasma 'Candidatus Phytoplasma mali'. BMC Genomics 9, 306.

Kuboyama, T., Huang, C. C., Lu, X., Sawayanagi, T., Kanazawa, T., Kagami, T., Matsuda, I., Tsuchizaki, T. \& Namba, S. (1998). A plasmid isolated from phytopathogenic onion yellows phytoplasma and its heterogeneity in the pathogenic phytoplasma mutant. Mol Plant Microbe Interact 11, 1031-1037.

Lee, I. M., Davis, R. E. \& Gundersen-Rindal, D. E. (2000). Phytoplasma: phytopathogenic mollicutes. Annu Rev Microbiol 54, 221-255.

Liefting, L. W., Shaw, M. E. \& Kirkpatrick, B. C. (2004). Sequence analysis of two plasmids from the phytoplasma beet leafhoppertransmitted virescence agent. Microbiology 150, 1809-1817.

Liefting, L. W., Andersen, M. T., Lough, T. J. \& Beever, R. E. (2006). Comparative analysis of the plasmids from two isolates of "Candidatus Phytoplasma australiense". Plasmid 56, 138-144.

Mulligan, M. E., Hawley, D. K., Entriken, R. \& McClure, W. R. (1984). Escherichia coli promoter sequences predict in vitro RNA polymerase selectivity. Nucleic Acids Res 12, 789-800.

Neelakanta, G., Li, X., Pal, U., Liu, X., Beck, D. S., DePonte, K., Fish, D., Kantor, F. S. \& Fikrig, E. (2007). Outer surface protein B is critical for Borrelia burgdorferi adherence and survival within Ixodes ticks. PLoS Pathog 3, e33.

Nishigawa, H., Miyata, S., Oshima, K., Sawayanagi, T., Komoto, A., Kuboyama, T., Matsuda, I., Tsuchizaki, T. \& Namba, S. (2001). In planta expression of a protein encoded by the extrachromosomal DNA of a phytoplasma and related to geminivirus replication proteins. Microbiology 147, 507-513.

Nishigawa, H., Oshima, K., Kakizawa, S., Jung, H. Y., Kuboyama, T., Miyata, S., Ugaki, M. \& Namba, S. (2002a). Evidence of intermolecular recombination between extrachromosomal DNAs in phytoplasma: a trigger for the biological diversity of phytoplasma? Microbiology 148, 1389-1396.

Nishigawa, H., Oshima, K., Kakizawa, S., Jung, H. Y., Kuboyama, T., Miyata, S., Ugaki, M. \& Namba, S. (2002b). A plasmid from a noninsect-transmissible line of a phytoplasma lacks two open reading frames that exist in the plasmid from the wild-type line. Gene 298, 195-201.

Nishigawa, H., Oshima, K., Miyata, S., Ugaki, M. \& Namba, S. (2003). Complete set of extrachromosomal DNAs from three pathogenic lines of onion yellows phytoplasma and use of PCR to differentiate each line. J Gen Plant Pathol 69, 194-198. 
Oshima, K., Kakizawa, S., Nishigawa, H., Kuboyama, T., Miyata, S., Ugaki, M. \& Namba, S. (2001a). A plasmid of phytoplasma encodes a unique replication protein having both plasmid- and virus-like domains: clue to viral ancestry or result of virus/plasmid recombination? Virology 285, 270-277.

Oshima, K., Shiomi, T., Kuboyama, T., Sawayanagi, T., Nishigawa, H., Kakizawa, S., Miyata, S., Ugaki, M. \& Namba, S. (2001b). Isolation and characterization of derivative lines of the onion yellows phytoplasma that do not cause stunting or phloem hyperplasia. Phytopathology 91 , 1024-1029.

Oshima, K., Kakizawa, S., Nishigawa, H., Jung, H. Y., Wei, W., Suzuki, S., Arashida, R., Nakata, D., Miyata, S. \& other authors (2004). Reductive evolution suggested from the complete genome sequence of a plantpathogenic phytoplasma. Nat Genet 36, 27-29.

Pal, U., Yang, X., Chen, M., Bockenstedt, L. K., Anderson, J. F., Flavell, R. A., Norgard, M. V. \& Fikrig, E. (2004). OspC facilitates Borrelia burgdorferi invasion of Ixodes scapularis salivary glands. J Clin Invest 113, 220-230.

Purcell, A. H. (1982). Insect vector relationships with prokaryotic plant pathogens. Annu Rev Phytopathol 20, 397-417.

Shiomi, T., Tanaka, M., Wakiya, H. \& Zenbayashi, R. (1996). Occurrence of welsh onion yellows. Ann Phytopathol Soc Jpn 62, 258-260.

Sorensen, K. I., Baker, K. E., Kelln, R. A. \& Neuhard, J. (1993). Nucleotide pool-sensitive selection of the transcriptional start site in vivo at the Salmonella typhimurium pyrC and pyrD promoters. J Bacteriol 175, 4137-4144.

Stewart, P. E., Byram, R., Grimm, D., Tilly, K. \& Rosa, P. A. (2005). The plasmids of Borrelia burgdorferi: essential genetic elements of a pathogen. Plasmid 53, 1-13.

Suzuki, S., Oshima, K., Kakizawa, S., Arashida, R., Jung, H. Y., Yamaji, Y., Nishigawa, H., Ugaki, M. \& Namba, S. (2006). Interaction between the membrane protein of a pathogen and insect microfilament complex determines insect-vector specificity. Proc Natl Acad Sci U S A 103, 4252-4257.

Thomas, C. M. (2004). Evolution and population genetics of bacterial plasmids. In Plasmid Biology, pp. 509-528. Edited by B. E. Funnell. \& G. J. Phillips. Washington, DC: American Society for Microbiology.

Tran-Nguyen, L. T. T. \& Gibb, K. S. (2006). Extrachromosomal DNA isolated from tomato big bud and Candidatus Phytoplasma australiense phytoplasma strains. Plasmid 56, 153-166.
Vivian, A., Murillo, J. \& Jackson, R. W. (2001). The roles of plasmids in phytopathogenic bacteria: mobile arsenals? Microbiology 147, 763-780

Wade, J. T., Roa, D. C., Grainger, D. C., Hurd, D., Busby, S. J., Struhl, K. \& Nudler, E. (2006). Extensive functional overlap between sigma factors in Escherichia coli. Nat Struct Mol Biol 13, 806-814.

Wagner, L. A., Weiss, R. B., Driscoll, R., Dunn, D. S. \& Gesteland, R. F. (1990). Transcriptional slippage occurs during elongation at runs of adenine or thymine in Escherichia coli. Nucleic Acids Res 18, 35293535.

Webb, D. R., Bonfiglioli, R. G., Carraro, L., Osler, R. H. \& Symons, R. H. (1999). Oligonucleotides as hybridization probes to localize phytoplasmas in host plants and insect vectors. Phytopathology 89, 894-901.

Weiner, J., Herrmann, R. \& Browning, G. F. (2000). Transcription in Mycoplasma pneumoniae. Nucleic Acids Res 28, 4488-4496.

Weintraub, P. G. \& Beanland, L. (2006). Insect vectors of phytoplasmas. Annu Rev Entomol 51, 91-111.

Wilson, H. R., Chan, P. T. \& Turnbough, C. L., Jr (1987). Nucleotide sequence and expression of the pyrC gene of Escherichia coli K-12. J Bacteriol 169, 3051-3058.

Wilson, H. R., Archer, C. D., Liu, J. K. \& Turnbough, C. L., Jr (1992). Translational control of pyrC expression mediated by nucleotidesensitive selection of transcriptional start sites in Escherichia coli. J Bacteriol 174, 514-524.

Xiong, X. F. \& Reznikoff, W. S. (1993). Transcriptional slippage during the transcription initiation process at a mutant lac promoter in vivo. J Mol Biol 231, 569-580.

Yang, X. F., Pal, U., Alani, S. M., Fikrig, E. \& Norgard, M. V. (2004). Essential role for OspA/B in the life cycle of the Lyme disease spirochete. J Exp Med 199, 641-648.

Ye, F., Melcher, U. \& Fletcher, J. (1997). Molecular characterization of a gene encoding a membrane protein of Spiroplasma citri. Gene 189, 95-100.

Yu, J., Wayadande, A. C. \& Fletcher, J. (2000). Spiroplasma citri surface protein P89 implicated in adhesion to cells of the vector, Circulifer tenellus. Phytopathology 90, 716-722.

Edited by: J. Renaudin 